\title{
Osteoporotic fractures among foreign-born individuals: a national Swedish study
}

\author{
P. Wändell ${ }^{1}$ (D) X. Li ${ }^{2} \cdot$ A. C. Carlsson ${ }^{1,3} \cdot$ J. Sundquist ${ }^{2,4,5} \cdot$ K. Sundquist $^{2,4,5}$
}

Received: 23 April 2020 / Accepted: 10 August 2020 / Published online: 19 August 2020

(C) The Author(s) 2020

\begin{abstract}
Summary In this national study of osteoporotic fractures in foreign-born individuals, we found a lower risk of osteoporotic fractures in general among foreign-born individuals compared with Swedish-born, especially in immigrants from southern Europe. A higher risk was found among some groups, i.e. men and women from Bosnia and Iraq and men from Lebanon.

Introduction The aim of this study was to analyse risk of osteoporotic fractures in foreign-born individuals compared with Swedish-born individuals.

Methods This was a nationwide study of individuals 50 years of age and older $(N=2,775,736)$. Osteoporotic fractures were defined as at least one registered diagnosis of fractures in the hip, humerus, forearm or vertebrae, in the National Patient Register between January 1, 1998, and December 31, 2012. Cox regression analysis was used to estimate the relative risk (hazard ratios (HR) with 99\% confidence intervals (CI)) of incident osteoporotic fractures in foreign-born compared with Swedish-born individuals. The Cox regression models were stratified by sex and adjusted for age, comorbidities and sociodemographic status. Results A total of 362,899 osteoporotic fractures were registered (96,847 among men and 266,052 among women), with hip fractures dominating (54.0\% among men, $42.6 \%$ among women). Fully adjusted HRs (99\% CI) were for all immigrant men 0.75 (99\% CI, 0.73-0.78) and women 0.83 (99\% CI, 0.81-0.84), with significantly lower HRs among most groups but with higher HRs in certain countries. For the specific fractures, higher HRs were found for lower forearm fractures for men from Asia and for vertebral fractures among women from Asia.

Conclusions We observed a generally lower risk of osteoporotic fractures among first-generation immigrants, with few exceptions.
\end{abstract}

Keywords Forearm fractures · Gender · Hip fractures · Humerus fractures · Immigrants · Neighbourhood · Osteoporotic fractures $\cdot$ Socioeconomic status $\cdot$ Vertebral fractures

\section{Introduction}

The number of osteoporotic fractures is on the rise worldwide owing to an increasing elderly population. Osteoporotic fractures [1], most often including hip fractures, forearm fractures and vertebral fractures but also humerus fractures [2], are also associated with a significant all-cause mortality and increasing healthcare costs, especially in developed countries
Electronic supplementary material The online version of this article (https://doi.org/10.1007/s00198-020-05597-5) contains supplementary material, which is available to authorized users.

\section{P. Wändell}

per.wandell@ki.se

1 Division of Family Medicine and Primary Care, Department of Neurobiology, Care Sciences and Society, NVS Department, Karolinska Institutet, Alfred Nobels Allé 23, SE-141 83 Huddinge, Sweden

2 Center for Primary Health Care Research, Lund University, Malmö, Sweden
3 Academic Primary Health Care Centre, Stockholm Region, Stockholm, Sweden

4 Department of Family Medicine and Community Health, Department of Population Health Science and Policy, Icahn School of Medicine at Mount Sinai, New York, NY, USA

5 Center for Community-Based Healthcare Research and Education (CoHRE), Department of Functional Pathology, School of Medicine, Shimane University, Matsue, Japan 
[3], including the EU [4]. The geographic and ethnic patterns differ globally $[1,5]$, with hip fractures being of highest interest [6] but also other fractures, such as vertebral fractures [7, 8].

Osteoporotic fractures are especially high in Northern Europe. In a Norwegian study from the capital Oslo, the incidence of hip and forearm fractures was shown to be higher than in studies in other countries [9].

With an increasing number of immigrants in Europe during the last decades, the health and disease patterns in this group are of major interest. In Sweden, the proportion of firstgeneration immigrants, i.e. foreign-born individuals, in the population is around $17 \%$ [10]. As regards osteoporotic fractures in Sweden, the risk of hip fractures is shown to be lower among foreign-born compared with Swedish-born individuals $[11,12]$ and also of distal forearm fractures in first- and second-generation immigrants [13]. However, knowledge about other osteoporotic fractures in specific immigrant groups is scarce. In an earlier study on hip fractures, the incidence rates in individuals of Japanese ancestry living on Oahu, Hawaii, were on the same level as in Japanese living in Okinawa, Japan, but around half of that in Caucasians [14].

The aim of this study was to analyse national Swedish data as regards risk of osteoporotic fractures, including hip fractures, forearm fractures, vertebral fractures and forearm fractures, in several groups of first-generation immigrants compared with Swedish-born individuals. We hypothesise that the risk will be lower in general and in many groups of firstgeneration immigrants.

\section{Methods}

\section{Design}

In the present study, we used the Total Population Register and the National Patient Register (NPR). We included individuals aged 50 years of age and older to study firstgeneration immigrants compared with Swedish-born individuals. The follow-up period ran from January 1, 1998, until hospitalisation/out-patient treatment of an osteoporotic fracture at age of diagnosis of 50 years or more, death, emigration or the end of the study period on December 31, 2012, whichever came first. Out-patient diagnoses were included nationwide from 2001 and onwards from specialist open care but not primary health care as these diagnoses are not included in the NPR. We used a unique pseudonymized serial number for each individual which helped us to avoid double-counting.

\section{Outcome variable}

Osteoporotic fractures: humerus fractures (S42.2-S42.4), lower forearm fractures (S52.5 and S52.6), hip fractures (S72.0-
S72.2), vertebral fractures (S12 (including S12.0-S12.9), S22.0 and S22.1, S32.0, T08)

\section{Co-morbidities}

We also identified co-morbidities according to ICD-10 for the following hospital diagnoses during the entire study period: malignant neoplasms (C00-C97), endocrine disorders (including thyrotoxicosis E05, hyperparathyroidism E21, hypopituitarism E23.0, primary ovarian failure E28.3, testicular hypofunction E29.1), diabetes (E10-E14), alcoholism (F10), hypertension (I10-I19), cerebrovascular diseases (I60-69), COPD (J40-J47), liver disease (K70-K76), intestinal malabsorption (K90), rheumatoid arthritis (M05 and M06) and systemic connective tissue disorders (M30-M36).

\section{Demographic and socioeconomic variables}

\section{Age was used as a continuous variable in the analysis.}

Educational attainment was categorised as $\leq 9$ years (partial or complete compulsory schooling), 10-12 years (partial or complete secondary schooling) and $>12$ years (attendance at college and/or university).

Geographic region of residence was included in order to adjust for possible regional differences in hospital admissions and was categorised as (1) large cities with surrounding regions, (2) southern Sweden (southern and middle part of Sweden) and (3) northern Sweden (the five most northern regions). Large cities were defined as municipalities with a population of $>200,000$ and comprised the three largest cities in Sweden: Stockholm, Gothenburg and Malmö. Southern Sweden and northern Sweden included both rural regions and smaller towns, and the geographic boundary between northern and southern Sweden was set at the river Dalälven, which by tradition is regarded to be the natural boundary to northern Sweden.

\section{Neighbourhood deprivation}

Neighbourhood socioeconomic status (NSES): This index was categorised into four groups: more than one standard deviation (SD) below the mean (low deprivation level or high SES), more than one SD above the mean (high deprivation level or low SES) and within one SD of the mean (moderate SES or moderate deprivation level) used as reference group and also unknown neighbourhood SES [15].

\section{Statistical analysis}

Baseline data are presented with continuous variables as mean and standard deviations and categorical variables as counts and percentages. We used Cox regression analysis to estimate 
the risk (hazard ratios (HR) with $99 \%$ confidence intervals (CI)) of incident osteoporotic fractures in different firstgeneration immigrant groups compared with the control group, i.e. Swedish-born, during the follow-up time. All analyses were stratified by sex. Three models were used: model 1 with adjustment for age and region of residence in Sweden; model 2 with adjustment for age, region of residence in Sweden, educational level, marital status and neighbourhood SES, to examine to what extent SES explained the association between country of birth and fracture incidence; and model 3 as model 2 but with the inclusion of relevant co-morbidities, to examine if other diagnoses explained the association between country of birth and osteoporotic fracture incidence.

\section{Results}

Baseline data are shown in Table 1 and 2, with a total of $2,775,736$ individuals 50 years of age and above included, i.e. 325,991 foreign-born (164,492 men, 161,499 women), and 2,449,745 Swedish-born (1,370,750 men, 1,311,995 women) (data for all men and women, respectively, in Supplementary Table 1). A total of 362,899 osteoporotic fractures were registered, i.e. 96,847 among men and 266,052 among women. Out of the fractures, hip fractures were most common, 54.0\% among all osteoporotic fractures among men and $42.6 \%$ among women. However, among Swedish-born, the rate of hip fractures out of all studied osteoporotic fractures was more common than among foreign-born, while low forearm fractures were less common. Most fractures were noted in the age interval 70-79 years of age, i.e. $34.4 \%$ among men and $34.3 \%$ among women. Co-morbidities were, in general, more common among individuals with osteoporotic fractures than without, also among Swedish- and foreign-born women, with the exception of cancer among Swedish-born women (Table 1 and 2).

Having a higher educational level showed higher risk for fractures, especially among foreign-born individuals (Table 3 and 4). The risk was lower in individuals living in southern or northern Sweden compared with the large cities and for married individuals. Regarding co-morbidities, estimates were increased for most co-morbidities, except for hypertension (lower among Swedish-born men and women, and non-significant among foreign-born men and women), but decreased for cancer among Swedish-born women and non-significant for intestinal malabsorption and systematic connective tissue disorders for foreign-born men. Highest HRs were seen for alcoholism, for both Swedish-born men and women and foreignborn men and women (HRs 2.21-3.15).

In Table 5 the fracture risk in general for osteoporotic fractures for men and women is shown, with lower risk in general for all foreign-born individuals (number of all individuals and cases in Supplementary Table 2; with numbers in relation to stay in Sweden in Supplementary Table 3). Most regions or specific countries showed lower risks compared with Swedish-born men and women; however with nonsignificant estimates in full models for men from Baltic countries in general, Northern America and Russia. For specific countries (Supplementary Table 4), higher risks in all models were found among men from Iraq; in models $1-3$, the HRs (99\% CI) were 1.36 (1.02-1.80), 1.77 (1.34-2.35) and 1.79 (1.35-2.37), respectively. In models 2 and 3, the HRs were among men from Bosnia, 1.82 (1.32) and 1.78 (1.29-2.46), respectively, and, in the fully adjusted model (Model 3 ) in men from Lebanon, 1.51 (1.01-2.27). Among women (Supplementary Table 5), a higher risk was found only in models 2 and 3 and among women from Norway; the HRs were 1.07 (1.01-1.13) and 1.05 (1.00-1.11), respectively. Risks with fully adjusted models for the specific osteoporotic fractures are shown in Table 6 with a higher risk of forearm fractures among men from Asia and, for vertebral fractures, among women from Asia. Even if risk estimates were similar for the specific fractures in relation to all osteoporotic fractures, however, with fewer statistically significant results, this was most evident for vertebral fractures, and to some extent for humerus and forearm fractures. As regards specific countries (Supplementary Tables 6 and 7), a significantly higher risk (shown as HR; 99\% CI) was found for lower forearm and hip fractures for men from Bosnia (1.78; 1.03-3.06), Turkey (1.52; 1.02-2.25), Lebanon (2.39; 1.26-4.53 and Iraq (1.85; $1.12-3.05)$.

\section{Discussion}

The main results of this study were that the risk of osteoporotic fractures in general was lower among first-generation men and women compared with Swedish-born. A higher risk was only observed in some specific groups, i.e. consistently so in men from Iraq in all statistical models and, for specific fractures the in fully adjusted models, in men from Asia (for distal forearm fractures) and in women from Asia (for vertebral fractures).

The risk of osteoporotic fractures is very high in northern Europe, hence, why a lower risk among first-generation immigrants compared with Swedish-born is not surprising. This is also shown in earlier Swedish studies of hip fractures [11, 12] and distal forearm fractures [13]. Furthermore, a lower risk of forearm fractures among Asian immigrants in Norway has also been found [9].

The earlier Swedish studies of hip fractures included individuals from 16 years [11] and 50 years of age [12], respectively, and with data from 1987-1999 [11] to 1987-2002 [12], respectively. In the 2010 study by Albin et al. [11], the risk was lower among all foreign-born individuals; the overall odds ratio (OR) was 0.82 , with a higher risk only among men from Iceland/Norway, OR 1.13, and a similar risk among 
Table 1. Population and number of cases of osteoporotic fractures in men

\begin{tabular}{|c|c|c|c|c|c|c|c|c|}
\hline & \multicolumn{4}{|c|}{ Swedish-born } & \multicolumn{4}{|c|}{ Foreign born } \\
\hline & \multicolumn{2}{|l|}{ Population } & \multicolumn{2}{|c|}{$\begin{array}{l}\text { Osteoporotic } \\
\text { fractures }\end{array}$} & \multicolumn{2}{|c|}{ Population } & \multicolumn{2}{|c|}{$\begin{array}{l}\text { Osteoporotic } \\
\text { fractures }\end{array}$} \\
\hline & No. & $\%$ & No & $\%$ & No. & $\%$ & No & $\%$ \\
\hline Total population & $1,137,750$ & & 89,733 & & 164,492 & & 7114 & \\
\hline \multicolumn{9}{|l|}{ Subtype of events } \\
\hline Humerus fractures & & & 13,261 & 14.8 & & & 1188 & 16.7 \\
\hline Low forearm fractures & & & 14,575 & 16.2 & & & 1731 & 24.3 \\
\hline Hip fractures & & & 49,256 & 54.9 & & & 3058 & 43.0 \\
\hline Vertebral fractures & & & 12,641 & 14.1 & & & 1137 & 16.0 \\
\hline \multicolumn{9}{|l|}{ Age (years) } \\
\hline $50-59$ & 447,600 & 39.3 & 19,037 & 21.2 & 84,859 & 51.6 & 2338 & 32.9 \\
\hline $60-69$ & 294,690 & 25.9 & 20,190 & 22.5 & 49,845 & 30.3 & 2198 & 30.9 \\
\hline $70-79$ & 249,602 & 21.9 & 31,363 & 35.0 & 23,566 & 14.3 & 1956 & 27.5 \\
\hline$\geq 80$ & 145,858 & 12.8 & 19,143 & 21.3 & 6222 & 3.8 & 622 & 8.7 \\
\hline \multicolumn{9}{|l|}{ Educational level } \\
\hline$\leq 9$ & 547,053 & 48.1 & 47,220 & 52.6 & 91,861 & 55.8 & 3155 & 44.3 \\
\hline $10-12$ & 228,003 & 20.0 & 17,517 & 19.5 & 26,942 & 16.4 & 1541 & 21.7 \\
\hline$>12$ & 362,694 & 31.9 & 24,996 & 27.9 & 45,689 & 27.8 & 2418 & 34.0 \\
\hline \multicolumn{9}{|l|}{ Region of residence } \\
\hline Large cities & 365,628 & 32.1 & 31,476 & 35.1 & 60,548 & 36.8 & 3553 & 49.9 \\
\hline Southern Sweden & 527,435 & 46.4 & 41,544 & 46.3 & 44,195 & 26.9 & 2594 & 36.5 \\
\hline Northern Sweden & 244,687 & 21.5 & 16,713 & 18.6 & 59,749 & 36.3 & 967 & 13.6 \\
\hline \multicolumn{9}{|l|}{ Marital status } \\
\hline Married & 885,874 & 77.9 & 67,169 & 74.9 & 130,075 & 79.1 & 5032 & 70.7 \\
\hline Not married & 251,876 & 22.1 & 22,564 & 25.1 & 34,417 & 20.9 & 2082 & 29.3 \\
\hline \multicolumn{9}{|l|}{ Neighbourhood deprivation } \\
\hline Low & 182,199 & 16.0 & 12,925 & 14.4 & 13,247 & 8.1 & 784 & 11.0 \\
\hline Middle & 599,642 & 52.7 & 49,077 & 54.7 & 47,381 & 28.8 & 2760 & 38.8 \\
\hline High & 124,103 & 10.9 & 10,758 & 12.0 & 18,417 & 11.2 & 1056 & 14.8 \\
\hline Unknown & 231,806 & 20.4 & 16,973 & 18.9 & 85,447 & 51.9 & 2514 & 35.3 \\
\hline Hospital diagnosis of COPD & 88,840 & 7.8 & 10,508 & 11.7 & 11,426 & 6.9 & 1061 & 14.9 \\
\hline $\begin{array}{l}\text { Hospital diagnosis of } \\
\text { diabetes }\end{array}$ & 142,412 & 12.5 & 13,142 & 14.6 & 19,215 & 11.7 & 1259 & 17.7 \\
\hline $\begin{array}{l}\text { Hospital diagnosis of } \\
\text { alcoholism }\end{array}$ & 35,820 & 3.1 & 5387 & 6.0 & 4714 & 2.9 & 615 & 8.6 \\
\hline Hospital diagnosis of stroke & 175,183 & 15.4 & 21,042 & 23.4 & 17,257 & 10.5 & 1628 & 22.9 \\
\hline $\begin{array}{l}\text { Hospital diagnosis of } \\
\text { hypertension }\end{array}$ & 298,500 & 26.2 & 25,293 & 28.2 & 34,051 & 20.7 & 2278 & 32.0 \\
\hline Hospital diagnosis of cancer & 303,808 & 26.7 & 26,894 & 30.0 & 28,206 & 17.1 & 1981 & 27.8 \\
\hline $\begin{array}{l}\text { Hospital diagnosis of liver } \\
\text { disease }\end{array}$ & 11,585 & 1.0 & 1307 & 1.5 & 1518 & 0.9 & 141 & 2.0 \\
\hline $\begin{array}{l}\text { Hospital diagnosis of } \\
\text { endocrine disorders }\end{array}$ & 9076 & 0.8 & 937 & 1.0 & 1208 & 0.7 & 99 & 1.4 \\
\hline $\begin{array}{l}\text { Hospital diagnosis of } \\
\text { systemic connective tissue } \\
\text { disorders }\end{array}$ & 16,489 & 1.4 & 1839 & 2.0 & 1255 & 0.8 & 106 & 1.5 \\
\hline $\begin{array}{l}\text { Hospital diagnosis of } \\
\text { rheumatoid arthritis }\end{array}$ & 13,796 & 1.2 & 1635 & 1.8 & 1245 & 0.8 & 134 & 1.9 \\
\hline $\begin{array}{l}\text { Hospital diagnosis of } \\
\text { intestinal malabsorption }\end{array}$ & 2711 & 0.2 & 308 & 0.3 & 158 & 0.1 & 12 & 0.2 \\
\hline All & 113,7750 & 100.0 & 89,733 & 100.0 & 16,4492 & 100.0 & 7114 & 100.0 \\
\hline
\end{tabular}

$C O P D$ chronic obstructive pulmonary disease 
Table 2 Population and number of cases of osteoporotic fractures in women

\begin{tabular}{|c|c|c|c|c|c|c|c|c|}
\hline & \multicolumn{4}{|c|}{ Swedish-born } & \multicolumn{4}{|c|}{ Foreign-born } \\
\hline & \multicolumn{2}{|l|}{ Population } & \multicolumn{2}{|l|}{ Events } & \multicolumn{2}{|c|}{ Population } & \multicolumn{2}{|l|}{ Events } \\
\hline & No. & $\%$ & No & $\%$ & No. & $\%$ & No & $\%$ \\
\hline Total population & $1,311,995$ & & 245,486 & & 161,499 & & 20,566 & \\
\hline \multicolumn{9}{|l|}{ Subtype of events } \\
\hline Humerus fractures & & & 46,627 & 19.0 & & & 3902 & 19.0 \\
\hline Low forearm fractures & & & 76,395 & 31.1 & & & 8371 & 40.7 \\
\hline Hip fractures & & & 106,460 & 43.4 & & & 6814 & 33.1 \\
\hline Vertebral fractures & & & 16,004 & 6.5 & & & 1479 & 7.2 \\
\hline \multicolumn{9}{|l|}{ Age (years) } \\
\hline $50-59$ & 461,985 & 35.2 & 47,241 & 19.2 & 73,026 & 45.2 & 5205 & 25.3 \\
\hline $60-69$ & 318,812 & 24.3 & 55,061 & 22.4 & 49,818 & 30.8 & 6559 & 31.9 \\
\hline $70 v 79$ & 311,110 & 23.7 & 84,807 & 34.5 & 29,203 & 18.1 & 6476 & 31.5 \\
\hline$\geq 80$ & 220,088 & 16.8 & 58,377 & 23.8 & 9452 & 5.9 & 2326 & 11.3 \\
\hline \multicolumn{9}{|l|}{ Educational level } \\
\hline$\leq 9$ & 700,005 & 53.4 & 147,279 & 60.0 & 95,597 & 59.2 & 10,991 & 53.4 \\
\hline $10-12$ & 363,200 & 27.7 & 61,709 & 25.1 & 35,611 & 22.1 & 5391 & 26.2 \\
\hline$>12$ & 248,790 & 19.0 & 36,498 & 14.9 & 30,291 & 18.8 & 4184 & 20.3 \\
\hline \multicolumn{9}{|l|}{ Region of residence } \\
\hline Large cities & 434,045 & 33.1 & 86,752 & 35.3 & 62,655 & 38.8 & 9919 & 48.2 \\
\hline Southern Sweden & 612,897 & 46.7 & 114,481 & 46.6 & 49,162 & 30.4 & 7651 & 37.2 \\
\hline Northern Sweden & 265,053 & 20.2 & 44,253 & 18.0 & 49,682 & 30.8 & 2996 & 14.6 \\
\hline \multicolumn{9}{|l|}{ Marital status } \\
\hline Married & $1,069,274$ & 81.5 & 186,477 & 76.0 & 141,416 & 87.6 & 16,677 & 81.1 \\
\hline Not married & 242,721 & 18.5 & 59,009 & 24.0 & 20,083 & 12.4 & 3889 & 18.9 \\
\hline \multicolumn{9}{|l|}{ Neighbourhood deprivation } \\
\hline Low & 194,570 & 14.8 & 34,053 & 13.9 & 13,981 & 8.7 & 2200 & 10.7 \\
\hline Middle & 713,264 & 54.4 & 136,888 & 55.8 & 55,067 & 34.1 & 8886 & 43.2 \\
\hline High & 152,496 & 11.6 & 29,300 & 11.9 & 19,752 & 12.2 & 2835 & 13.8 \\
\hline Unknown & 251,665 & 19.2 & 45,245 & 18.4 & 72,699 & 45.0 & 6645 & 32.3 \\
\hline Hospital diagnosis of COPD & 106,912 & 8.1 & 24,390 & 9.9 & 12,911 & 8.0 & 2620 & 12.7 \\
\hline Hospital diagnosis of diabetes & 127,633 & 9.7 & 26,916 & 11.0 & 15,769 & 9.8 & 2593 & 12.6 \\
\hline Hospital diagnosis of alcoholism & 13,516 & 1.0 & 3692 & 1.5 & 2011 & 1.2 & 523 & 2.5 \\
\hline Hospital diagnosis of stroke & 177,517 & 13.5 & 44,891 & 18.3 & 16,777 & 10.4 & 3692 & 18.0 \\
\hline Hospital diagnosis of hypertension & 356,966 & 27.2 & 77,779 & 31.7 & 41,217 & 25.5 & 7279 & 35.4 \\
\hline Hospital diagnosis of cancer & 279,069 & 21.3 & 50,671 & 20.6 & 25,922 & 16.1 & 4088 & 19.9 \\
\hline Hospital diagnosis of liver disease & 10,065 & 0.8 & 2222 & 0.9 & 1241 & 0.8 & 225 & 1.1 \\
\hline Hospital diagnosis of endocrine disorders & 28,512 & 2.2 & 6430 & 2.6 & 3139 & 1.9 & 562 & 2.7 \\
\hline Hospital diagnosis of systemic connective tissue disorders & 37,356 & 2.8 & 8689 & 3.5 & 3287 & 2.0 & 677 & 3.3 \\
\hline Hospital diagnosis of rheumatoid arthritis & 31,845 & 2.4 & 7543 & 3.1 & 3202 & 2.0 & 686 & 3.3 \\
\hline Hospital diagnosis of intestinal malabsorption & 4177 & 0.3 & 895 & 0.4 & 302 & 0.2 & 64 & 0.3 \\
\hline All & $1,311,995$ & 100.0 & 245,486 & 100.0 & 161,499 & 100.0 & 20,566 & 100.0 \\
\hline
\end{tabular}

$C O P D$ chronic obstructive pulmonary disease

women from Denmark compared with Swedish-born women, OR 0.98. In the 2015 study by Johansson et al. [12], the overall risk among foreign-born individuals was around half of that of Swedish-born. Besides, even if the incidence increased slightly by time after immigration, it remained on a substantially lower level than among Swedish-born. In comparison with the present study, where we included individuals from 50 years of age and older, we also found lower risks of 
Table 3 Incidence of osteoporotic fractures in Swedishborn and foreign-born men expressed as hazard ratios (HR) with $99 \%$ confidence intervals (99\% CI)

\begin{tabular}{|c|c|c|c|c|c|c|}
\hline \multirow[b]{3}{*}{ Birth year } & \multicolumn{3}{|c|}{ Born in Sweden } & \multicolumn{3}{|c|}{ Foreign-born } \\
\hline & \multirow{2}{*}{$\frac{\mathrm{HR}^{*}}{0.94}$} & \multicolumn{2}{|c|}{$99 \% \mathrm{CI}$} & \multirow{2}{*}{$\frac{\mathrm{HR}^{*}}{0.93}$} & \multicolumn{2}{|c|}{$99 \% \mathrm{CI}$} \\
\hline & & 0.94 & 0.94 & & 0.93 & 0.93 \\
\hline \multicolumn{7}{|l|}{ Time of stay in Sweden (ref. $\geq 30$ years) } \\
\hline Unknown & & & & 0.94 & 0.85 & 1.04 \\
\hline$<10$ & & & & 1.82 & 1.54 & 2.14 \\
\hline $10-19$ & & & & 0.95 & 0.82 & 1.10 \\
\hline $20-29$ & & & & 0.85 & 0.77 & 0.93 \\
\hline \multicolumn{7}{|l|}{ Educational level (ref. $\leq 9$ years) } \\
\hline $10-12$ & 1.08 & 1.05 & 1.10 & 1.26 & 1.14 & 1.38 \\
\hline$>12$ & 1.03 & 1.00 & 1.05 & 1.19 & 1.10 & 1.29 \\
\hline \multicolumn{7}{|l|}{ Region of residence (ref. Large cities) } \\
\hline Southern Sweden & 0.71 & 0.69 & 0.73 & 0.85 & 0.78 & 0.93 \\
\hline Northern Sweden & 0.49 & 0.48 & 0.51 & 0.35 & 0.31 & 0.39 \\
\hline Marital status (ref. Married) & 0.72 & 0.70 & 0.73 & 0.78 & 0.72 & 0.84 \\
\hline \multicolumn{7}{|l|}{ Neighbourhood deprivation (ref. Low) } \\
\hline Middle & 1.11 & 1.08 & 1.15 & 1.01 & 0.90 & 1.13 \\
\hline High & 1.14 & 1.10 & 1.19 & 1.02 & 0.88 & 1.16 \\
\hline Unknown & 0.57 & 0.55 & 0.59 & 0.71 & 0.62 & 0.80 \\
\hline Hospitalization of COPD & 1.40 & 1.36 & 1.45 & 1.57 & 1.43 & 1.73 \\
\hline Hospitalization diabetes & 1.15 & 1.12 & 1.18 & 1.19 & 1.09 & 1.30 \\
\hline Hospitalization of alcoholism & 2.57 & 2.46 & 2.68 & 3.15 & 2.77 & 3.59 \\
\hline Hospitalization of stroke & 1.42 & 1.38 & 1.45 & 1.53 & 1.40 & 1.66 \\
\hline Hospitalization of hypertension & 0.89 & 0.87 & 0.91 & 1.03 & 0.96 & 1.11 \\
\hline Hospitalization of cancer & 1.10 & 1.08 & 1.12 & 1.25 & 1.16 & 1.35 \\
\hline Hospitalization of liver disease & 1.21 & 1.11 & 1.31 & 1.24 & 0.96 & 1.60 \\
\hline Hospitalization of endocrine disorders & 1.23 & 1.12 & 1.35 & 1.43 & 1.07 & 1.91 \\
\hline Hospitalization of rheumatoid arthritis & 1.50 & 1.39 & 1.61 & 1.81 & 1.41 & 2.33 \\
\hline Hospitalization of intestinal malabsorption & 1.49 & 1.27 & 1.75 & 1.35 & 0.59 & 3.07 \\
\hline Hospitalization of systemic connective tissue disorders & 1.14 & 1.06 & 1.22 & 1.07 & 0.81 & 1.41 \\
\hline
\end{tabular}

*Fully adjusted: COPD: Chronic obstructive pulmonary disease hip fractures among all foreign-born men and women with fully adjusted HRs of 0.70 and 0.78 , respectively. In our present study, we had the opportunity to provide more granularity in terms of country of origin and type of fractures, with a significantly lower risk in foreign-born individuals from most regions of the world.

In a recent study of ours on distal forearm fractures, individuals from 20 years of age and older were included [13] and with the same follow-up as in the present study. In that study, the fully adjusted HR among all foreign-born men and women was 0.95 , with an increased risk by region for men from Asia; the fully adjusted HR for men born in Asia was 1.17. Notably, an increased risk for specific countries in all models was found in men from Bosnia, Poland, Turkey and Iraq and in women from Iraq. Besides, the HRs among second-generation immigrants overall were on a similar level as in first-generation immigrants. In the present study, we found a lower overall risk of distal forearm fractures among immigrants; the fully adjusted HRs were 0.89 among men and 0.93 among women, respectively, with a significantly lower risk among men from most regions of the world, except among men from Asia; the fully adjusted HR for men born in Asia was 1.43. The risk was significantly lower only in women from Southern Europe and North and Latin America. Thus, the results for our two studies are quite similar, but with a slightly lower relative risk compared to Swedish-born men and women when only including individuals of 50 years of age and above, compared with those of 20 years of age and above.

The osteoporotic risk was especially low among immigrants from southern Europe. One question is whether higher 25-hydroxyvitamin D levels could be of importance, but the 25-hydroxyvitamin D levels have actually been shown to be higher in northern Europe, which could be owed to a higher intake of fish and vitamin D supplements $[16,17]$. Otherwise the 25-hydroxyvitamin D levels have been shown to be low, or actually very low, among non-Western immigrants to the 
Table 4 Incidence of osteoporotic fractures in Swedishborn and foreign-born women expressed as hazard ratios (HR) with $99 \%$ confidence intervals $(99 \% \mathrm{CI})$

\begin{tabular}{|c|c|c|c|c|c|c|}
\hline \multirow[b]{3}{*}{ Birth year } & \multicolumn{3}{|c|}{ Born in Sweden } & \multicolumn{3}{|c|}{ Foreign born } \\
\hline & \multirow{2}{*}{$\begin{array}{c}\mathrm{HR}^{*} \\
0.94\end{array}$} & \multicolumn{2}{|c|}{$99 \% \mathrm{CI}$} & \multirow{2}{*}{$\frac{\mathrm{HR}^{*}}{0.93}$} & \multicolumn{2}{|c|}{$99 \% \mathrm{CI}$} \\
\hline & & 0.94 & 0.94 & & 0.93 & 0.93 \\
\hline \multicolumn{7}{|l|}{ Time of stay in Sweden (ref. $\geq 30$ years) } \\
\hline Unknown & & & & 0.85 & 0.80 & 0.90 \\
\hline$<10$ & & & & 1.38 & 1.20 & 1.59 \\
\hline $10-19$ & & & & 0.80 & 0.71 & 0.90 \\
\hline $20-29$ & & & & 0.82 & 0.77 & 0.87 \\
\hline \multicolumn{7}{|l|}{ Educational level (ref. $\leq 9$ years) } \\
\hline $10-12$ & 1.03 & 1.02 & 1.05 & 1.20 & 1.14 & 1.26 \\
\hline$>12$ & 1.01 & 0.99 & 1.03 & 1.20 & 1.14 & 1.27 \\
\hline \multicolumn{7}{|l|}{ Region of residence (ref. Large cities) } \\
\hline Southern Sweden & 0.80 & 0.79 & 0.81 & 0.78 & 0.74 & 0.82 \\
\hline Northern Sweden & 0.64 & 0.63 & 0.66 & 0.42 & 0.39 & 0.44 \\
\hline Marital status (ref. Married) & 0.86 & 0.85 & 0.87 & 0.91 & 0.86 & 0.96 \\
\hline \multicolumn{7}{|l|}{ Neighbourhood deprivation (ref. Low) } \\
\hline Middle & 1.03 & 1.01 & 1.05 & 1.05 & 0.98 & 1.12 \\
\hline High & 1.03 & 1.00 & 1.05 & 0.99 & 0.91 & 1.07 \\
\hline Unknown & 0.72 & 0.70 & 0.73 & 0.66 & 0.61 & 0.71 \\
\hline Hospitalization of COPD & 1.28 & 1.26 & 1.31 & 1.36 & 1.28 & 1.45 \\
\hline Hospitalization diabetes & 1.07 & 1.05 & 1.09 & 1.08 & 1.01 & 1.15 \\
\hline Hospitalization of alcoholism & 2.21 & 2.10 & 2.32 & 2.58 & 2.26 & 2.94 \\
\hline Hospitalization of stroke & 1.18 & 1.16 & 1.20 & 1.27 & 1.20 & 1.34 \\
\hline Hospitalization of hypertension & 0.95 & 0.94 & 0.97 & 1.02 & 0.98 & 1.07 \\
\hline Hospitalization of cancer & 0.98 & 0.97 & 0.99 & 1.06 & 1.01 & 1.12 \\
\hline Hospitalization of liver disease & 1.24 & 1.17 & 1.32 & 1.17 & 0.96 & 1.42 \\
\hline Hospitalization of endocrine disorders & 1.14 & 1.10 & 1.18 & 1.16 & 1.03 & 1.31 \\
\hline Hospitalization of rheumatoid arthritis & 1.36 & 1.31 & 1.40 & 1.50 & 1.34 & 1.68 \\
\hline Hospitalization of intestinal malabsorption & 1.29 & 1.17 & 1.42 & 1.65 & 1.16 & 2.36 \\
\hline Hospitalization of systemic connective tissue disorders & 1.09 & 1.06 & 1.13 & 1.13 & 1.01 & 1.27 \\
\hline
\end{tabular}

*Fully adjusted; COPD: Chronic obstructive pulmonary disease
Nordic countries [18]. Peak bone mass develops during childhood and early adulthood and is thus dependent on factors during this period in life, i.e. levels of physical activity and vitamin $\mathrm{D}$, and also of dietary factors [19]. These factors are also of importance to maintain bone quality during later life. The effect of low 25-hydroxyvitamin D levels in adult immigrants could be expected only to modulate the risk of osteoporosis later in life, and supplements with vitamin D and calcium may prevent fractures among the elderly population [20].

Another factor of importance could be the "healthy migrant" effect, i.e. that migrants tend to have a better health status than their compatriots in the country of origin [21]. This might be true for several groups, especially for migrants from other Nordic or European countries or migrants from North America.

In addition, hormone replacement therapy in women may lower the fracture risk [22]; this treatment, however, is given more restrictedly due to increased health risks, such as breast cancer [23], stroke and venous thromboembolism [24]. We had no information on differences in hormone replacement therapy between Swedish and immigrant women.

It is interesting that the risk was higher in some specific groups, i.e. for osteoporotic fractures in men from Iraq, and for distal forearm fractures in fully adjusted models in men from Asia, especially from countries in the Middle East region, and for vertebral fractures in fully adjusted models in women from Asia. Interestingly, the Iraqi group has the highest rate of refugees in Sweden together with the Bosnian group [25], and Middle Eastern countries have been war-torn. The higher risk in some specific countries could indicate that environmental factors are important for the global differences concerning incidence of osteoporotic fractures. Furthermore, an increased fracture risk in foreign-born men and women was observed during the first 10 years of stay in Sweden. However, there are racial/ethnic differences in bone 
Table 5 Incidence of osteoporotic fractures in foreignborn men and women vs Swedish-born men and women, respectively, expressed as hazard ratios (HR) with $99 \%$ confidence intervals $(99 \% \mathrm{CI})$

\begin{tabular}{|c|c|c|c|c|c|c|c|c|c|c|}
\hline & \multirow[b]{2}{*}{ Obs. } & \multicolumn{3}{|c|}{ Model 1} & \multicolumn{3}{|c|}{ Model 2} & \multicolumn{3}{|c|}{ Model 3} \\
\hline & & HR & \multicolumn{2}{|c|}{$99 \% \mathrm{CI}$} & HR & \multicolumn{2}{|c|}{$99 \% \mathrm{CI}$} & HR & \multicolumn{2}{|c|}{$99 \% \mathrm{CI}$} \\
\hline Sweden & 89,733 & 1 & & & 1 & & & 1 & & \\
\hline All foreign born & 7114 & 0.68 & 0.65 & 0.70 & 0.74 & 0.72 & 0.77 & 0.75 & 0.73 & 0.78 \\
\hline Nordic countries & 3563 & 0.74 & 0.70 & 0.78 & 0.82 & 0.78 & 0.86 & 0.81 & 0.77 & 0.85 \\
\hline Southern Europe & 266 & 0.33 & 0.28 & 0.39 & 0.40 & $\mathbf{0 . 3 3}$ & 0.47 & 0.43 & 0.36 & 0.51 \\
\hline Western Europe & 826 & 0.59 & 0.54 & 0.66 & 0.66 & 0.59 & 0.72 & 0.67 & 0.61 & 0.74 \\
\hline Eastern Europe & 530 & 0.60 & 0.53 & 0.68 & 0.61 & 0.54 & 0.70 & 0.64 & 0.57 & 0.73 \\
\hline Baltic countries & 336 & 0.86 & 0.73 & 1.00 & 0.91 & 0.78 & 1.07 & 0.91 & 0.78 & 1.06 \\
\hline Central Europe & 516 & 0.69 & 0.61 & 0.78 & 0.69 & 0.61 & 0.78 & 0.71 & 0.62 & 0.80 \\
\hline Africa & 91 & 0.54 & 0.40 & 0.73 & 0.62 & 0.46 & 0.84 & 0.65 & 0.48 & 0.88 \\
\hline Northern America & 183 & 0.76 & 0.62 & 0.94 & 0.86 & 0.69 & 1.06 & 0.86 & 0.70 & 1.07 \\
\hline Latin America & 96 & 0.45 & 0.34 & 0.61 & 0.51 & 0.38 & 0.68 & 0.56 & 0.42 & 0.75 \\
\hline Asia & 587 & 0.78 & 0.69 & 0.87 & 0.92 & 0.82 & 1.04 & 0.97 & 0.86 & 1.09 \\
\hline Russia & 115 & 0.95 & 0.73 & 1.24 & 0.96 & 0.74 & 1.26 & 0.95 & 0.73 & 1.24 \\
\hline \multicolumn{11}{|l|}{ Women } \\
\hline Sweden & 245,486 & 1 & & & 1 & & & 1 & & \\
\hline All foreign born & 20,566 & 0.78 & 0.72 & 0.79 & 0.83 & 0.81 & 0.84 & 0.83 & 0.81 & 0.84 \\
\hline Nordic countries & 12,821 & 0.84 & 0.81 & 0.86 & 0.89 & 0.82 & 0.86 & 0.88 & 0.87 & 0.91 \\
\hline Southern Europe & 402 & 0.34 & 0.29 & 0.39 & 0.39 & $\mathbf{0 . 3 0}$ & 0.39 & 0.41 & 0.34 & 0.45 \\
\hline Western Europe & 2580 & 0.73 & 0.69 & 0.77 & 0.78 & 0.69 & 0.78 & 0.78 & 0.74 & 0.82 \\
\hline Eastern Europe & 926 & 0.67 & 0.61 & 0.73 & 0.69 & 0.61 & 0.74 & 0.71 & 0.63 & 0.76 \\
\hline Baltic countries & 851 & 0.80 & 0.72 & 0.88 & 0.84 & 0.72 & 0.88 & 0.84 & 0.76 & 0.93 \\
\hline Central Europe & 1207 & 0.77 & 0.71 & 0.84 & 0.79 & 0.71 & 0.84 & 0.79 & 0.72 & 0.85 \\
\hline Africa & 58 & 0.60 & 0.42 & 0.88 & 0.69 & 0.47 & 1.00 & 0.71 & 0.49 & 1.03 \\
\hline Northern America & 462 & 0.76 & 0.66 & 0.86 & 0.82 & 0.72 & 0.94 & 0.82 & 0.72 & 0.94 \\
\hline Latin America & 210 & 0.57 & 0.47 & 0.70 & 0.64 & 0.47 & 0.69 & 0.65 & 0.52 & 0.77 \\
\hline Asia & 729 & 0.73 & 0.66 & 0.82 & 0.81 & 0.66 & 0.82 & 0.83 & 0.73 & 0.90 \\
\hline Russia & 308 & 0.87 & 0.74 & 1.02 & 0.89 & 0.76 & 1.05 & 0.89 & 0.75 & 1.04 \\
\hline
\end{tabular}

Model 1: adjusted for age and region of residence in Sweden; model 2: adjusted for age, region of residence in Sweden, educational level, marital status, and neighbourhood deprivation; model 3: model 2 + comorbidities. metabolism [26, 27], which could indicate genetic factors as being important. However, the present study could not address if the differences in fracture rates are related to race/ethnicity, genetic factors or environmental/societal factors, including lifestyle and dietary factors.

There are certain limitations with this study. We performed many statistical analyses, but subsequently used 99\% CI to partly compensate for multiple testing. However, we consider the overall results to be more valid, and results for specific regions of the world, and especially for specific countries, should be interpreted with more caution. We chose to include fractures of the hip, forearm, vertebrae and humerus as osteoporotic fractures, as these are often considered to be the most important and relevant osteoporotic fractures [2]. Sometimes, other fractures could also be included [4], e.g. fractures of the pelvis, rib, tibia, fibula, clavicle, scapula, sternum or other femoral fractures.
Fractures are mostly treated at emergency departments of hospitals hence why the coverage could be regarded as high, even if fractures in some cases in northern Sweden are treated at some specific primary healthcare centres. Besides, vertebral fractures are most probably under-reported, but also most probably on the same level in Swedish- and foreign-born individuals. For some of the co-morbidities, the results might have been biased, as COPD, diabetes and hypertension are mostly treated in primary care, and the NPR does not include diagnoses from primary care [28]. Otherwise, the validity of Swedish patient registers is regarded to be high [29].

In conclusion, we found a lower risk of osteoporotic fractures among foreign-born individuals compared with Swedish-born, with some exceptions. A higher risk was found among some specific groups of foreign-born individuals, i.e. men from Iraq, and also for specific fractures for distal 
Table 6 Incidence of osteoporotic fractures in foreign-born men and women vs Swedish-born men and women, respectively, expressed as hazard ratios (HR) with $99 \%$ confidence intervals $(99 \% \mathrm{CI})$

\begin{tabular}{|c|c|c|c|c|c|c|c|c|c|c|c|c|}
\hline & \multicolumn{3}{|c|}{ Humerus fractures } & \multicolumn{3}{|c|}{ Low forearm fratures } & \multicolumn{3}{|c|}{ Hip fractures } & \multirow[b]{2}{*}{ HR } & \multicolumn{2}{|c|}{ Vertebral fractures } \\
\hline & HR & $99 \% \mathrm{C}$ & & HR & $99 \% \mathrm{C}$ & & HR & $99 \%$ & & & $99 \% \mathrm{CI}$ & \\
\hline \multicolumn{13}{|l|}{ Men } \\
\hline Sweden & 1 & & & 1 & & & 1 & & & 1 & & \\
\hline All foreign-born & 0.74 & 0.68 & 0.81 & 0.89 & 0.83 & 0.96 & 0.70 & 0.66 & 0.74 & 0.77 & 0.70 & 0.84 \\
\hline Nordic countries & 0.77 & 0.68 & 0.87 & 0.88 & 0.79 & 0.98 & 0.81 & 0.75 & 0.86 & 0.79 & 0.70 & 0.90 \\
\hline Southern Europe & 0.55 & 0.37 & 0.80 & 0.46 & 0.32 & 0.66 & 0.36 & 0.27 & 0.49 & 0.49 & 0.32 & 0.74 \\
\hline Western Europe & 0.64 & 0.50 & 0.82 & 0.79 & 0.64 & 0.96 & 0.59 & 0.51 & 0.69 & 0.85 & 0.68 & 1.07 \\
\hline Eastern Europe & 0.70 & 0.53 & 0.94 & 0.93 & 0.75 & 1.16 & 0.44 & 0.35 & 0.55 & 0.69 & 0.51 & 0.93 \\
\hline Baltic countries & 1.05 & 0.72 & 1.53 & 1.23 & 0.86 & 1.74 & 0.83 & 0.66 & 1.03 & 0.94 & 0.61 & 1.44 \\
\hline Central Europe & 0.78 & 0.58 & 1.05 & 0.87 & 0.67 & 1.13 & 0.63 & 0.52 & 0.76 & 0.70 & 0.50 & 0.98 \\
\hline Africa & 0.45 & 0.21 & 1.00 & 0.98 & 0.61 & 1.56 & 0.48 & 0.27 & 0.84 & 0.62 & 0.30 & 1.30 \\
\hline Northern America & 0.67 & 0.37 & 1.23 & 0.48 & 0.24 & 0.93 & 1.10 & 0.84 & 1.42 & 0.78 & 0.43 & 1.39 \\
\hline Latin America & 0.47 & 0.23 & 0.96 & 0.87 & 0.55 & 1.37 & 0.36 & 0.21 & 0.64 & 0.53 & 0.25 & 1.10 \\
\hline Asia & 0.84 & 0.62 & 1.13 & 1.43 & 1.18 & 1.74 & 0.72 & 0.58 & 0.89 & 0.89 & 0.66 & 1.21 \\
\hline Russia & 1.03 & 0.52 & 2.01 & 1.05 & 0.54 & 2.06 & 0.88 & 0.61 & 1.27 & 1.19 & 0.62 & 2.29 \\
\hline \multicolumn{13}{|l|}{ Women } \\
\hline Sweden & 1 & & & 1 & & & 1 & & & 1 & & \\
\hline All foreign-born & 0.76 & 0.72 & 0.79 & 0.93 & 0.90 & 0.96 & 0.78 & 0.76 & 0.81 & 0.93 & 0.86 & 1.01 \\
\hline Nordic countries & 0.80 & 0.76 & 0.85 & 0.97 & 0.93 & 1.01 & 0.87 & 0.83 & 0.91 & 0.95 & 0.86 & 1.05 \\
\hline Southern Europe & 0.39 & 0.28 & 0.54 & 0.47 & 0.38 & 0.58 & 0.36 & 0.27 & 0.47 & 0.51 & 0.30 & 0.85 \\
\hline Western Europe & 0.74 & 0.65 & 0.84 & 0.94 & 0.86 & 1.02 & 0.72 & 0.65 & 0.79 & 0.85 & 0.68 & 1.05 \\
\hline Eastern Europe & 0.55 & 0.44 & 0.69 & 0.91 & 0.80 & 1.03 & 0.49 & 0.40 & 0.61 & 0.85 & 0.60 & 1.22 \\
\hline Baltic countries & 0.80 & 0.64 & 1.02 & 1.05 & 0.89 & 1.24 & 0.77 & 0.66 & 0.90 & 0.87 & 0.59 & 1.26 \\
\hline Central Europe & 0.79 & 0.66 & 0.94 & 0.88 & 0.78 & 1.00 & 0.66 & 0.57 & 0.77 & 0.95 & 0.71 & 1.28 \\
\hline Africa & 0.48 & 0.19 & 1.25 & 0.81 & 0.48 & 1.36 & 0.67 & 0.32 & 1.40 & 0.80 & 0.19 & 3.32 \\
\hline Northern America & 0.78 & 0.57 & 1.08 & 0.67 & 0.51 & 0.88 & 0.98 & 0.81 & 1.18 & 0.96 & 0.59 & 1.55 \\
\hline Latin America & 0.59 & 0.39 & 0.91 & 0.75 & 0.57 & 0.98 & 0.47 & 0.30 & 0.75 & 0.57 & 0.24 & 1.34 \\
\hline Asia & 0.64 & 0.50 & 0.82 & 0.97 & 0.84 & 1.13 & 0.59 & 0.47 & 0.75 & 1.48 & 1.07 & 2.05 \\
\hline Russia & 1.07 & 0.76 & 1.51 & 1.09 & 0.83 & 1.43 & 0.69 & 0.52 & 0.91 & 1.07 & 0.60 & 1.91 \\
\hline
\end{tabular}

*:Fully adjusted.

Bold figures denote statistically significant values

forearm fractures in men from Asia, especially from the Middle East region, and for vertebral fractures in women from Asia. On the other hand, an especially lower risk was found among immigrants from southern Europe. Different factors could be of importance for the differences being found, and further studies on risk factors of osteoporotic fractures among immigrants are warranted. Furthermore, studies of secondgeneration immigrants could be of value.

\section{Acknowledgements We thank Patrick Reilly for language editing.}

Funding information Open access funding provided by Karolinska Institute. This work was supported by ALF funding awarded to Jan Sundquist and Kristina Sundquist and by grants from the Swedish Research Council (awarded to Kristina Sundquist).

\section{Compliance with Ethical Standards}

Conflicts of Interest None.

Ethical approval All procedures performed in studies involving human participants were in accordance with the ethical standards of the institutional and/or national research committee and with the 1964 Helsinki declaration and its later amendments or comparable ethical standards.

Informed consent was not applicable, as the study was based on anonymised data from registers.

The study was approved by the regional ethics boards at Karolinska Institutet and Lund University.

The authors are not allowed to share the used data from the data sources being used.

Open Access This article is licensed under a Creative Commons Attribution-NonCommercial 4.0 International License, which permits any non-commercial use, sharing, adaptation, distribution and 
reproduction in any medium or format, as long as you give appropriate credit to the original author(s) and the source, provide a link to the Creative Commons licence, and indicate if changes were made. The images or other third party material in this article are included in the article's Creative Commons licence, unless indicated otherwise in a credit line to the material. If material is not included in the article's Creative Commons licence and your intended use is not permitted by statutory regulation or exceeds the permitted use, you will need to obtain permission directly from the copyright holder. To view a copy of this licence, visit http://creativecommons.org/licenses/by-nc/4.0/.

\section{References}

1. Cauley JA, Chalhoub D, Kassem AM, Fuleihan Gel H (2014) Geographic and ethnic disparities in osteoporotic fractures. Nat Rev Endocrinol 10:338-351

2. Abtahi S, Driessen JHM, Vestergaard P, van den Bergh J, Boonen A, de Vries F, Burden AM (2019) Secular trends in major osteoporotic fractures among 50+ adults in Denmark between 1995 and 2010. Osteoporos Int 30:2217-2223

3. Johnell O, Kanis JA (2006) An estimate of the worldwide prevalence and disability associated with osteoporotic fractures. Osteoporos Int 17:1726-1733

4. Hernlund E, Svedbom A, Ivergard M, Compston J, Cooper C, Stenmark J, McCloskey EV, Jonsson B, Kanis JA (2013) Osteoporosis in the European Union: medical management, epidemiology and economic burden. A report prepared in collaboration with the International Osteoporosis Foundation (IOF) and the European Federation of Pharmaceutical Industry Associations (EFPIA). Arch Osteoporos 8:136

5. Wang XF, Seeman E (2012) Epidemiology and structural basis of racial differences in fragility fractures in Chinese and Caucasians. Osteoporos Int 23:411-422

6. Johnell O, Kanis JA (2004) An estimate of the worldwide prevalence, mortality and disability associated with hip fracture. Osteoporos Int 15:897-902

7. Ballane G, Cauley JA, Luckey MM, El-Hajj Fuleihan G (2017) Worldwide prevalence and incidence of osteoporotic vertebral fractures. Osteoporos Int 28:1531-1542

8. Bow CH, Cheung E, Cheung CL, Xiao SM, Loong C, Soong C, Tan KC, Luckey MM, Cauley JA, Fujiwara S, Kung AWC (2012) Ethnic difference of clinical vertebral fracture risk. Osteoporos Int 23:879-885

9. Lofthus CM, Frihagen F, Meyer HE, Nordsletten L, Melhuus K, Falch JA (2008) Epidemiology of distal forearm fractures in Oslo, Norway. Osteoporos Int 19:781-786

10. Statistics Sweden (2016) Foreign-born persons in Sweden by country of birth, age and sex. Year 2000 - 2015. Statistics Sweden, Stockholm. http://www.statistikdatabasen.scb.se/pxweb/sv/ssd/ START_BE_BE0101_BE0101E/UtrikesFoddaR/?rxid= b4a34c1b-bd89-4621-8bd4-606c8809678a

11. Albin B, Hjelm K, Elmstahl S (2010) Lower prevalence of hip fractures in foreign-born individuals than in Swedish-born individuals during the period 1987-1999. BMC Musculoskelet Disord 11: 203

12. Johansson H, Oden A, Lorentzon M, McCloskey E, Kanis JA, Harvey NC, Karlsson MK, Mellstrom D (2015) Is the Swedish
FRAX model appropriate for Swedish immigrants? Osteoporos Int 26:2617-2622

13. Wändell P, Li X, Carlsson AC, Sundquist J, Sundquist K (2020) Distal forearm fractures in immigrant groups: a national Swedish study. Bone 138:115508

14. Ross PD, Norimatsu H, Davis JW, Yano K, Wasnich RD, Fujiwara S, Hosoda Y, Melton LJ 3rd (1991) A comparison of hip fracture incidence among native Japanese, Japanese Americans, and American Caucasians. Am J Epidemiol 133:801-809

15. Zoller B, Li X, Sundquist J, Sundquist K (2013) Neighbourhood deprivation and hospitalization for atrial fibrillation in Sweden. Europace 15:1119-1127

16. Lips P (2007) Vitamin D status and nutrition in Europe and Asia. J Steroid Biochem Mol Biol 103:620-625

17. Lips P (2010) Worldwide status of vitamin D nutrition. J Steroid Biochem Mol Biol 121:297-300

18. Wandell PE (2013) Population groups in dietary transition. Food Nutr Res 57:21668

19. Sandhu SK, Hampson G (2011) The pathogenesis, diagnosis, investigation and management of osteoporosis. J Clin Pathol 64: $1042-1050$

20. Avenell A, Mak JC, O'Connell D (2014) Vitamin D and vitamin D analogues for preventing fractures in post-menopausal women and older men. Cochrane Database Syst Rev:CD000227. https://doi. org/10.1002/14651858.CD000227.pub4

21. Kennedy S, Kidd MP, McDonald JT, Biddle N (2015) The Healthy Immigrant Effect: Patterns and Evidence from Four Countries. J Int Migr Integr 16:317-332

22. Dasarathy J, Labrador H (2018) Bone Health in Women. Prim Care 45:643-657

23. Beral V, Million Women Study C (2003) Breast cancer and hormone-replacement therapy in the Million Women Study. Lancet 362:419-427

24. Rossouw JE, Anderson GL, Prentice RL et al (2002) Risks and benefits of estrogen plus progestin in healthy postmenopausal women: principal results From the Women's Health Initiative randomized controlled trial. JAMA 288:321-333

25. Wandell P, Carlsson AC, Li X, Gasevic D, Arnlov J, Holzmann MJ, Sundquist J, Sundquist K (2018) Heart failure in immigrant groups: a cohort study of adults aged 45 years and over in Sweden. Scand Cardiovasc J 52:292-300

26. Gutierrez OM, Farwell WR, Kermah D, Taylor EN (2011) Racial differences in the relationship between vitamin $\mathrm{D}$, bone mineral density, and parathyroid hormone in the National Health and Nutrition Examination Survey. Osteoporos Int 22:1745-1753

27. Redmond J, Jarjou LM, Zhou B, Prentice A, Schoenmakers I (2014) Ethnic differences in calcium, phosphate and bone metabolism. Proc Nutr Soc 73:340-351

28. Carlsson AC, Wandell P, Osby U, Zarrinkoub R, Wettermark B, Ljunggren G (2013) High prevalence of diagnosis of diabetes, depression, anxiety, hypertension, asthma and COPD in the total population of Stockholm, Sweden - a challenge for public health. BMC Public Health 13:670

29. Ludvigsson JF, Andersson E, Ekbom A, Feychting M, Kim JL, Reuterwall C, Heurgren M, Olausson PO (2011) External review and validation of the Swedish national inpatient register. BMC Public Health 11:450

Publisher's note Springer Nature remains neutral with regard to jurisdictional claims in published maps and institutional affiliations. 